Observations over Europe, the only part of the world where they are numerous enough for the purpose, have also shown a most extraordinarily close correlation between the temperature and pressure of the air in the upper part of the troposphere, many of the coefficients exceeding 0.90 . These facts must be reckoned with in any theory about the formation of cyclones.

My own belief is that pressure differences originate in the upper half of the troposphere from variations in the strength of the surrounding winds. Being given the means of originating and maintaining a difference of pressure at about the height of $9 \mathrm{~km}$., the rest of the phenomena follow readily. The distribution of temperature, the high positive correlation below and the negative correlation above, and the rise and fall of the tropopause between cyclone and anticyclone are all explained by the vertical motion of the air that would naturally follow from the distribution of pressure.

Benson, November I2.

\section{Physiological Method as a Key to the Causation of Isle of Wight Bisease in Bees.}

IN the summer of 1918, while working with Prof. L. Hill and Mr. T. A. Webster on gas research, I advised Dr. John Rennie, of the natural history department of the University of Aberdeen, that a physiological study of metabolism in healthy bees and in bees known to be suffering from symptoms of Isle of Wight disease should be undertaken, making use of oxygen and carbon dioxide determinations. As a corollary, an investigation into the temperature of bees, healthy and unhealthy, was also indicated.

In the summer of. IgIg it was found that apparently bees infected with. Isle of Wight disease consumed in a given time much less oxygen than healthy controls. This observation was not. reported to me until July, Iy20, when I was able at once to draw the conclusion that the symptoms of Isle of Wight disease. were due to blocking of tracheal tubes and anoxæmia. Loss of the power of flight was to be expected, as the co-ordinating nervous mechanism and the musculature involved were deprived of their proper oxygen supply.

$\mathrm{Had}$ I been made acquainted with the results of a research I had.advised, or had the investigator been able to draw a very simple physiological conclusion from the data, whether the data were correct or erroneous, the discovery of a parasite as the blocking agent or disturbing factor in tracheal tubes would have been the natural consequence.

In 1920 this parasite was discovered by anatomical study, and its presence as the agent causing the disease is announced in the Press as the outcome of the researches of Dr. John Rennie, Mr. P. Bruce White, and Miss Elsie J. Harvey.

It will be noted that the physiological method of investigation could have led equally surely to the discovery of the parasite and to the interpretation of the symptoms.

Halesowen, November 5 .

\section{Luminosity by Attrition.}

I AM very glad that Sir Ray Lankester has again directed attention to this phenomenon. By a slip of the pen he says (November 4, p. 310) "quartz pebbles" in his first paragraph and in the heading. My object in writing is to say that these pebbles may be found on any shingle beach, and may be known by their translucent appearance under a "rotten" (or pitted) exterior. They are pale brown, and, when dry, look like lumps of derelict toffee. But on the shíngle beaches of South Devon (notably the "Budleigh Salterton Pebbles"), the Chesil Beach, and the Suffolk NO. 2664 , VOL. IO6] coast (notably at Aldeburgh) practically every pebble on the beach will "flash."

It is much to be desired that some mineralogist should take up the intensive study of flint, chert, and quartzite. I may mention that for many years I have stored every "peculiar" flint pebble I have come across, and my entire collection is at the service (as a gift) of any museum worker who cares to undertake the study.

Large Acres, Selsey Bill, Sussex,

$$
\text { November } 12 .
$$

The recent letters in Nature from Lieut.-Comdr. Damant and Sir E. Ray Lankester recall some observations made in 1916 in collaboration with my friend and former headmaster, the late Mr. W. P. Workman, who first directed my attention to this interesting phenomenon. Specimens of translucent quartz from a quarry about three miles from Tintagel, North Cornwall, give the characteristic orangecoloured light in broad daylight and the peculiur smell. This triboluminescence of quartz was observed by Du Fay in 1735 , and about 1748 Delius mentioned the sulphurous smell which accompanies the glow when quartz is rubbed against quartz (Kayser, Bd. iv., pp. 6r4, 6r7; Winkelmann, Bd. vi., p. 8og).

The following observations present, I believe, some points of novelty: (I) Luminescence is produced when quartz is rubbed by any material, such as topaz or sapphire, which is harder than itself. Dr. Gordon, head of the geological department of King's College, London, kindly lent a number of minerals for the purpose of this test. Ordinary steel, which falls below quartz in the scale of hardness, does not cause the glow. (2) Fused quartz, as sunnlied by the Silica Syndicate, gives a very fine effect. I have on several occasions shown this as a lecture experiment by rubbing together two tubes of transparent fused silica. In this connection the observation of Lord Rayleigh (NATURE, vol. civ., D. I53, I9ro) that "silica glass" possesses a remarkable crystalline or quasicrystalline structure is of special interest. (3) The tubes of fused quartz when rubbed together give the same peculiar odour as ordinary quartz pebbles.

It should, therefore, be possible to carry out an experiment of the kind suggested by Sir E. Rav Lankester by grinding the interior of a quartz vessel which might be highly evacuated or contain suitable liquid or gaseous reagents. According to Lord Rayleigh's experiments (Royal Society, February 27, I919), the clearest and whitest quartz has some power of scattering light, though much less than that of glass or liquids. This small scattering is considered to be due to inclusions, as in the case of visibly smoky or yellow quartz. May not the presence of minute diffused metallic particles, or perhaps particles of silicon itself, be the cause of the various phenomena under discussion? H. S. Allen.

The University, Edinburgh.

\section{Gontractile Vacuoles.}

THERE is no doubt that the explanation of the production of these vacuoles as given in NATURE of November II by Prof. Henry $H$. Dixon is the correct one. It may perhaps be of interest to Prof. Dixon to refer to a paper by $W$. Stempell published in I914 in Zoolog. Jahrb., Abt. allg. Zoot. u. Physiol. der Tiere (Bd. 34, iii., p. 437), where the same. view is put forward. I believe that this journal is not very accessible - a fact which doubtless accounts for its having been overlooked. I may say that it is my custom to teach this view, and a brief account will be found on p. 162 of my "Principles of General Physiology."
W. M. Bayliss. 